\title{
A influência da família e o papel do enfermeiro na promoção do aleitamento materno
}

\author{
Rosilene Batista Bullon \\ Fátima Aparecida Cardoso ${ }^{2}$ \\ Henry Maia Peixoto ${ }^{3}$ \\ Luciana Farias de Miranda ${ }^{4}$
}

\section{Resumo}

A promoção do aleitamento materno é a intervenção com o maior potencial para diminuição da morbimortalidade infantil, além de estimular o vínculo mãe-bebê e ser importante para a saúde materna. O leite materno é o melhor alimento para o recém-nascido obter um crescimento saudável. Não depende apenas de uma decisão de amamentar ou não, mas do conjunto de interações e conflitos sociais vivenciados pela nutriz. Este trabalho discute a influência da família no aleitamento materno. Objetiva discorrer sobre o papel do pai no aleitamento materno; conhecer o papel da mulher-avó neste período e identificar a atuação do profissional de enfermagem neste contexto. Trata-se de uma pesquisa bibliográfica, baseada na análise de publicações relacionadas com o tema, do período de 1985 a 2009. Para que o aleitamento materno seja uma prática consolidada, é necessária a atuação contínua do Estado, instituições e profissionais de saúde, comunidade e família, em especial o pai e as avós.

Palavras-chave: Aleitamento materno. Pai. Mulher-avó. Atuação do enfermeiro.

${ }^{1}$ Graduanda em Enfermagem, UniCEUB. E-mail: lebullon@hotmail.com

${ }^{2}$ Mestre em Ciências da Saúde; Professora da Faculdade de Enfermagem da FEPECS, SES, DF. E-mail: fafacardoso@gmail.com

${ }^{3}$ Graduado em Enfermagem; Especialista em Saúde do Adolescente; Especialista em Saúde da Família; Professor das Faculdades de Enfermagem UniCEUB e LS. E-mail: henrymp9@ hotmail.com

${ }^{4}$ Graduada em Enfermagem; Especialista em Gestão do Programa Saúde da Família; Especialista em Enfermagem Obstétrica; Orientadora de Prática da Faculdade de Enfermagem UniCEUB. E-mail: lumiranda_rj@yahoo.com.br 


\section{Introdução}

A Organização Mundial de Saúde (OMS) orienta que o leite materno deve ser ofertado à criança exclusivamente até os seis meses de vida, para posteriormente, serem introduzidos alimentos saudáveis na dieta do infante, mantendo-se o processo até os dois anos ou mais. Para tanto, é necessário o fortalecimento de ações que beneficiem o ato de aleitar como estratégia fundamental ao combate às práticas inadequadas de alimentação infantil para uma melhor qualidade de vida das crianças (REGO, 2002).

A secreção láctea da mulher é composta por proteínas do soro, como a lactoalbumina, lactoferrina, lisozima, imunoglobulinas, especialmente imunoglobulina. A secretória coagula-se em micropartículas em forma de flocos, facilitando a passagem para o intestino delgado. Seu consumo compensa pelo seu alto valor biológico, devido principalmente à lactoalbumina, que é própria para a espécie humana, sem nenhuma dificuldade de digestão, e compõe algo decisivo na síntese da lactose (SANTOS, 2005).

A proteína do leite humano oferece qualitativamente todos os aminoácidos em quantidades adequadas para o recém-nascido, fato ainda mais importante quando se trata de prematuros que apresentam deficiência bioquímica ou funcional (RICCO; DEL CIAMPO; ALMEIDA, 2004).

No leite humano são encontrados, principalmente: potássio, cálcio, fósforo, cloro e sódio; o ferro, o cobre e o manganês, não necessitando de suplementação oral para crianças amamentadas ao seio (SANTOS, 2005).

As características bioquímicas e imunológicas do leite humano conferem uma constituição ideal e incomparável a qualquer outro tipo de leite. Bacteriologicamente é seguro e imunologicamente apresenta fatores de proteção e de defesa contra infecções, em especial, as gastrointestinais (SANTOS, 2005).

Quanto à quantidade de água, o Aleitamento Materno Exclusivo (AME) é suficiente para manter o lactente hidratado e com diurese adequada, mesmo em clima seco e quente. Devido a isso, podemos dispensar a oferta de água ou chás. As reduzidas taxas de sais e de proteínas no leite humano oferecem menor carga osmolar ao trabalho renal, o que garante a estabilidade hídrica do lactente (RICCO; DEL CIAMPO; ALMEIDA, 2004). 
O Aleitamento Materno (AM) favorece o desenvolvimento da estrutura facial, da mastigação, da fala e do alinhamento dos dentes e respiração, além de reduzir o risco das doenças crônicas como diabetes, hipertensão e arteriosclerose (MURAHOVSCHI et al., 1999).

Quando pesquisamos os benefícios do AM, verificamos que a promoção do AME é a intervenção isolada em saúde pública com o maior potencial para diminuição da mortalidade infantil e suas consequências para a saúde da criança (TOMA; REA, 2008).

Em vista disso, as políticas de promoção da saúde são muito importantes, pois, têm contribuído para a diminuição das taxas de mortalidade infantil. Em 1990 a taxa era de 47,1 por mil nascidos vivos e em 2008 a taxa diminuiu para 19,3 por mil nascidos vivos. Esses resultados são consequência de muitos fatores, como o aumento da cobertura vacinal, do pré-natal, da estratégia de saúde da família, da reidratação oral, do aumento da taxa de escolaridade da mãe e do incentivo ao aleitamento materno (BRASIL, 2009).

O AM também produz benefícios à saúde materna, influenciando os fenômenos regressivos do puerpério (loquiação e involução uterina) a ocorrerem com maior rapidez devido ao resultado da ação da ocitocina que, quando age sobre a musculatura do útero, previne a atonia uterina no pós-parto imediato, além de diminuir a probabilidade de nova gravidez e a incidência dos cânceres de mama e útero (SANTOS, 2005).

As vantagens psicossociais são as de estabelecer uma relação afetiva mãefilho que estimula o desenvolvimento psicomotor, social e mental. Torna-se parte fundamental da construção do psiquismo e da vida relacional do bebê e da transformação da identidade da mulher em mulher-mãe (FALCETO, 2002).

O fator econômico não pode deixar de ser considerado num país onde muitas famílias contam com poucos recursos para o seu sustento. Amamentar ao seio uma criança é mais barato do que o uso de leite artificial (GIUGLIANI, 1994).

Segundo Silva (1997), a prática real de amamentar é uma experiência que envolve uma série de fatores maternos e outros relacionados ao recém-nascido. Não depende, exclusivamente, de uma decisão tomada anteriormente de amamentar ou não, ou ainda, de conhecimentos sobre o assunto por parte da mulher. 
A prática da amamentação tem a interferência do "meio" em que a nutriz está inserida.

Quando mencionamos mamadeiras ou outros itens usados pelo recém-nascido, nos vêm à mente bicos e chupetas. Um estudo realizado em Porto Alegre confirmou a associação do uso de bicos e chupetas ao desmame precoce (SOARES et al., 2003).

No Brasil, a Agência Nacional de Vigilância Sanitária, com o objetivo de restringir a promoção do uso de chupetas e bicos, decidiu incluir na embalagem do produto a inscrição "O Ministério da Saúde adverte: a criança que mama no peito não necessita de mamadeira, bico ou chupeta”. Essa medida tem como finalidade desencorajar a mãe a trocar o aleitamento natural pelo artificial (LAMOUNIER, 2003).

Uma das melhores pessoas para auxiliar a nutriz é, sem dúvida, seu parceiro. Ele pode ajudar ao dizer que gostaria que sua companheira amamentasse, demonstrando conhecimento de que o leite dela é o melhor alimento para a criança, dentre outras formas (KING, 1998).

Segundo Santos (2005), há uma necessidade de "olharmos" para a puérpera com suas experiências, suas percepções, suas crenças e sua família, pois a influência de práticas culturais passadas de mãe para filha, através de gerações, é muito relevante nesse período. Quando a equipe de enfermagem e outros profissionais de saúde ignoram essas crenças, geram-se conflitos.

Tendo em mente a importância do AM, a necessidade de compreendê-lo e promovê-lo de forma exclusiva até os 06 meses de vida, a importância da família no processo, a necessidade de mais estudos que avaliem o impacto da inclusão da família em intervenções de promoção do AM, considera-se de grande relevância a realização do presente estudo.

O interesse por essa temática acerca da ação do profissional de enfermagem e da influência da família no Aleitamento Materno surgiu a partir de vivências nos programas de assistência a mulheres e crianças instalados em Unidades Básicas de Saúde e também da atuação em maternidades do Distrito Federal, onde observouse pouca ênfase na participação da família no processo de aleitamento.

O objetivo geral deste estudo é identificar como a família interfere no processo de AM, buscando entendê-lo para além da díade mãe-filho (a) tendo em vis- 
ta que os profissionais de enfermagem vêm somando esforços, a partir das orientações dos organismos nacionais e internacionais de saúde na promoção do AM que é tangenciado por múltiplas determinações que concorrem para o sucesso ou não desse ato que salva vidas.

Para que o apoio à amamentação seja eficaz, faz-se necessário debater o papel da família e do profissional enfermeiro na promoção do AM. Mediante os aspectos que cercam a família, temos como objetivos: discorrer sobre o papel do pai no aleitamento materno; conhecer o papel da mulher-avó no aleitamento materno, identificar a atuação do enfermeiro nas ações de estímulo ao aleitamento materno.

\section{Metodologia}

Trata-se de uma pesquisa bibliográfica, que procura abordar o papel da família no aleitamento materno, a partir de referências teóricas publicadas em documentos. Relatam Lakatos e Marconi (2001) que pesquisa bibliográfica é um estudo produzido por documentos e fontes secundárias, e busca todo documento tornado público em relação ao tema em estudo. A pesquisa foi baseada em bibliografias reconhecidas cientificamente, tais como: artigos, livros, manuais, publicações periódicas nacionais e internacionais todas publicadas no período de 1985 a 2009. Gil (2002) comenta que a principal vantagem da pesquisa bibliográfica consiste em possibilitar ao investigador contato com várias obras e opiniões muito mais amplas do que aquela que pesquisaria diretamente.

Foram analisados 14 conteúdos de sites oficiais como do Ministério da Saúde, Sociedade Brasileira de Pediatria, Sociedade Pediátrica de São Paulo, Conselho Regional de Enfermagem do Distrito Federal (COREN-DF), dentre outros. Pesquisados 36 artigos publicados, 9 dissertações, 4 teses e 31 periódicos, utilizando as bases de dados BIREME e Scielo. As pesquisas selecionadas trazem informações pertinentes à influência da família no Aleitamento Materno, enfatizando a participação do pai, da mulher-avó e atuação do enfermeiro.

Foram excluídos estudos que abordavam crianças no $1^{\circ}$ semestre de vida, porém não participantes do Aleitamento Materno exclusivo e após os seis meses de vida; estudos com crianças prematuras ou que tenham tido alguma intercorrência ao nascer. 


\section{Histórico do aleitamento materno}

A amamentação é algo biologicamente determinado, mas sofreu influências socioculturais, a partir da colonização do Brasil na qual o ato de amamentar não era considerado um ato nobre. No século XX observa-se um elevado desinteresse da sociedade brasileira no que se refere ao AM, deixando de ser realizada por muitas mães. Consequências disso já puderam ser observadas como aumento da desnutrição e mortalidade infantil. Porém, o efeito em longo prazo ainda é desconhecido, já que transformações genéticas não ocorrem com a rapidez de mudanças culturais. Alguns afirmam que o uso de leite não humano em crianças pequenas é o maior experimento não controlado envolvendo a espécie humana (GIUGLIANI, 2000).

Podemos citar alguns responsáveis pela diminuição do AM no século XX, como a industrialização, a urbanização, o uso da mão de obra da mulher que era mais barata, a desvalorização pela sociedade da maternidade e a descoberta das fórmulas de leite em pó. Ocorreram repercussões desastrosas na saúde das nossas crianças e das parturientes.

Após um período de decadência do AM, a partir dos anos 70 do século XX iniciou-se a réplica às consequências desastrosas do uso de leites de outras espécies, com o movimento de resgate à "cultura da amamentação" (LAMOUNIER; VIEIRA; GOUVÊA, 2001).

Durante a década de 1980, em todo o Brasil, as ações que mais se destacaram foram as de promoção e incentivo ao AM. Embora se falasse em atuação nas comunidades por meio de apoio às gestantes e nutrizes, na prática, tal fato se configurava como ações de incentivo a promoção do AM (MÜLLER, 2008).

No período entre 1991 a 2000, o Brasil reduziu sua mortalidade infantil em 38\%. Essa porcentagem representa a sobrevivência de aproximadamente 404.120 crianças menores de um ano. Conseguimos um índice próximo à média encontrada nas Américas, mas ainda precisamos trabalhar mais em prol do AME (BRASIL, 2004b).

Embora evidências mostrem a melhoria da situação do aleitamento materno entre as crianças brasileiras, a situação no país em relação AME é preocupante. O percentual de crianças no primeiro semestre de vida, alimentadas somente com o leite materno, permanece muito aquém do recomendado pela OMS (MONTE et al., 2002). 


\section{Avanço das políticas de incentivo ao aleitamento materno}

O Brasil lançou oficialmente em 1981 o Programa Nacional de Incentivo ao Aleitamento Materno (PNIAM), que tinha como estratégia operacionalizar ações de combate aos obstáculos para o estabelecimento da amamentação (MONSON, 1991).

O início dos anos 90 foi marcado por uma crescente e visível crise de paradigma de amamentação que embasava a política estatal, na medida em que o desmame precoce persistia como importante preocupação na agenda de Saúde pública, implicando em maior risco de agravo à saúde da criança por diarreias, desnutrição crônica, desidratação e aumentando os índices de mortalidade infantil (MONTEIRO, 2006).

A partir de 1992 foi dado o início no Brasil ao Programa Iniciativa Hospital Amigo da Criança (IHAC) que propunha mecanismos de desenvolvimento para proteção e apoio ao AM (MONTEIRO, 2006).

Para participar do movimento era necessária a adesão aos "Dez Passos para o Sucesso do Aleitamento Materno" e ao Código Internacional de Comercialização dos Substitutos do Leite Materno (BRASIL, 2008c).

Os dez passos são recomendações que favorecem a amamentação a partir de práticas e orientações no período pré-natal, no atendimento à mãe e ao recémnascido, ao longo do trabalho de parto, durante a internação após o parto e nascimento e no retorno ao domicílio, com apoio da comunidade. Os dez passos para o sucesso do AM são (OMS, 2001):

Ter uma norma escrita sobre aleitamento materno, que deve ser transmitida rotineiramente a toda equipe de cuidados de saúde;

Treinar toda a equipe de cuidados de saúde, capacitando-a para implementar esta norma;

Informar todas as gestantes sobre as vantagens e o manejo do aleitamento;

Ajudar as mães a iniciar o aleitamento na primeira meia hora após o nascimento;

Mostrar às mães como amamentar e como manter a lactação, mesmo se vierem a ser separadas de seus filhos; 
Não dar ao recém-nascidos nenhum outro alimento ou bebida além do leite materno, a não ser que tal procedimento seja indicado pelo médico;

Praticar o "alojamento conjunto" - permitir que as mães e os bebês permaneçam juntos 24 horas por dia;

Encorajar o aleitamento sob livre demanda;

Não dar bicos artificiais ou chupetas a crianças amamentadas ao seio;

Encorajar o estabelecimento de grupos de apoio ao aleitamento, para onde mães deverão ser encaminhadas por ocasião da alta hospitalar ou ambulatório;

A Semana Mundial da Amamentação (SMAM) de 2007 teve como tema: "Amamentação na Primeira Hora, Proteção sem Demora". Evidências científicas recentes comprovam que, se todas as mulheres iniciassem a amamentação na primeira hora de vida após o parto, um milhão de mortes de recém-nascidos poderia ser evitado (SOCIEDADE DE PEDIATRIA DE SÃO PAULO, 2007).

Pesquisa Nacional de Demografia e Saúde (PNDS), divulgada no início de julho de 2008, mostrou dados positivos: $43 \%$ das crianças são amamentadas na primeira hora de vida no Brasil, 99\% são amamentadas no primeiro dia de vida e $40 \%$ das crianças menores de seis meses recebem AME. Se levado em conta o tempo de duração, a região que mais amamenta é a Centro-Oeste, e a Norte seria a última no ranking nacional (BRASIL, 2008c).

A SMAM de 2008 teve como objetivo sensibilizar a família para a importância do apoio que a mulher precisa receber do companheiro, dos avôs, da comunidade, dos amigos, dos médicos, dos enfermeiros e de outros profissionais da saúde e do governo, afinal, "nada mais natural que amamentar e nada mais importante que apoiar". (BRASIL, 2008c).

O Ministério da Saúde (MS) instituiu a Rede Amamenta Brasil com o objetivo de reduzir a mortalidade infantil com o aumento dos índices de AM no país. Segundo a Portaria no 2.799 de 18 de novembro de 2008, o programa seria desenvolvido no Sistema Único de Saúde (SUS) de forma articulada com a rede de Bancos de Leite Humano, Rede Norte-Nordeste de Saúde Perinatal e com o Pacto Nacional pela redução da Mortalidade Materna e Neonatal e contaria com a participação de um representante de cada uma dessas instituições (BRASIL, 2008d). 
A Rede Brasileira de Bancos de Leite Humano é a maior e a mais complexa do mundo, composta por 194 unidades em operação e outras dez em fase de implantação. Foram distribuídos, no ano de 2007, 95.000 litros de leite humano pasteurizado, com qualidade certificada, a 136.527 recém-nascidos internados em unidades de terapia intensiva. Isso não seria possível se não houvesse a participação de mães que integram voluntariamente o programa de doação (BRASIL, 2008d).

O Brasil tem legislação específica para proteger o AM. A Norma Brasileira de Comercialização de Alimentos para Lactentes e Crianças de Primeira Infância, inclui bicos, chupetas e mamadeiras (Lei $\mathrm{n}^{\circ} 11.265$ ), como itens que podem influenciar o desmame. Essa Lei contribui para proteção e incentivo ao AME nos primeiros seis meses de vida e para proteção e incentivo à continuidade do aleitamento materno até os dois anos de idade, após a introdução de novos alimentos na dieta dos lactentes (BRASIL, 2006).

Em setembro de 2008, o Presidente da República sancionou a Lei 11.770, que estabelece a licença maternidade de seis meses, sem prejuízo do emprego e do salário, para as funcionárias públicas federais, ficando a critério dos Estados, Municípios e empresas privadas a adoção desta Lei (BRASIL, 2008a).

Dentre as atividades desenvolvidas visando à mobilização social, o Brasil comemora anualmente a Semana Mundial da Amamentação e o Dia Nacional de Doação de Leite Humano. As comemorações configuram-se como uma importante propaganda social capaz de aumentar os índices de AM, além de sensibilizar novas doadoras de leite humano (BRASIL, 2009).

\section{0 papel do pai no aleitamento materno}

Na gravidez, o homem e a mulher se tornam pai e mãe, ambos vivenciando essa mudança com expectativas, anseios e temores. O homem também sofre o impacto da mudança de papéis. O medo, a responsabilidade sobre o bebê que está no ventre da companheira, as alterações no comportamento dela, muitas vezes sem uma causa aparente, também levam o homem a viver uma fase tumultuosa (FREITAS; COELHO; SILVA, 2007). 
Ocorreram alguns avanços com respeito à participação do pai em dar apoio à mulher-gestante. Um deles é a Lei $\mathrm{n}^{\circ} 11.108$, de 7 de abril de 2005, que garante à parturiente o direito de um acompanhante, pode ser o pai ou outra pessoa, durante todo o período de trabalho de parto, parto e pós-parto imediato. Os serviços de saúde do Sistema Único de Saúde (SUS), da rede própria ou conveniada, ficam obrigados a permitir a presença, junto à parturiente.

Nesse momento do parto, o pai pode oferecer à companheira apoio emocional; isso significa aproximar-se de forma carinhosa, dizer palavras de encorajamento e fazer elogios. O apoio físico dá-se por meio de toques, massagens e do incentivo à deambulação e à mudanças de posição, buscando sempre oferecer conforto físico à mulher (MOTTA; CREPALDI, 2005).

O dia a dia do cuidado à saúde da mulher vem mostrando que a relação com o parceiro sexual influencia profundamente o bem-estar da mulher na gestação e após o nascimento dos (as) filhos (as), seja pela sua presença, aceitação e prazer de estar junto, seja pela sua ausência, resistência e negação da responsabilidade como pai. Quando a participação do homem é efetiva, na gravidez e após o parto, criam-se situações de bem-estar para todos os envolvidos no processo, de modo a se estabelecerem relações mais igualitárias (FREITAS; COELHO; SILVA; 2007).

Muitos pais reagem com inconformismo, raiva e até ciúme, pois é difícil aceitar sua nova posição no contexto familiar, dividir a atenção da esposa, realizar tarefas desagradáveis e renunciar a todos os privilégios que tinha antes da chegada do bebê. Essas emoções são normais, porque refletem o desajuste próprio de uma mudança na vida. É necessário superá-lo o quanto antes possível (GUERRERO, 1990).

Esse impacto da nova rotina pode arruinar o casamento dos novos pais. Esse momento nada "cor-de-rosa" da vida com o primeiro bebê foi esmiuçado por duas pesquisas realizadas pelas universidades americanas da Califórnia e de Washington, que entrevistaram cerca de 200 pais e mães de primeira viagem. As conclusões são tocantes. Mais da metade disse enfrentar crises conjugais sérias, 92\% afirmaram ter mais conflitos com o parceiro do que tinham antes e $20 \%$ se separaram até dois anos depois do nascimento do bebê (SALOMONE, 2005).

Para muitos homens, sentir-se pai é um fato que só ocorre posteriormente ao nascimento e, em alguns casos, mesmo após a chegada do filho, o sentimento de 
paternidade ainda não é tão perceptível, assim como o peso da responsabilidade que esse evento pressupõe (FREITAS; COELHO; SILVA; 2007).

Mas a única coisa que não é possível ao pai é amamentar. No resto, ele pode e deve participar junto à mãe. Durante todo o tempo da amamentação, o pai poderá ajudar nos afazeres da casa e no cuidados com os filhos. Precisamos estimular o pai a participar desde o pré-natal e não permitir que ele perca essa festa a que só a mãe parecia ter sido convidada. Com isso descobrirá intensas alegrias em acompanhar passo a passo o desenvolvimento da criança (LANA, 1999).

Relata Guerrero (1990) que, quando tudo ocorre normalmente, o bebê vincula-se primeiro com a mãe e sua relação com o pai acontece mais tarde. Isso não significa que o papel do pai no AM comece vários meses depois do nascimento de seu filho. O que ocorre é que sua participação nas etapas iniciais do processo é diferente. Consiste em compartilhar as experiências da esposa, dando-lhe apoio necessário desde a gestação e depois, para auxiliar e motivar a amamentação.

Como nos diz Ichisato e Shimo (2002), precisamos buscar o olhar do homem nesse processo do AM. Ele faz parte do apoio social que é tão necessário para o sucesso do AM. Isso ocorre quando compreendemos que a mulher precisa de suporte social no processo de adaptações ao papel materno, no qual o AM está inserido.

\section{0 papel da mulher-avó no estímulo ao aleitamento materno}

A longevidade humana vem permitindo o crescimento do número de famílias nas quais estão presentes três e mesmo quatro gerações. Diante das transformações ocorridas nos âmbito psicossocial e familiar, as avós aparecem como figuras peculiares ao expressarem, através de suas histórias, o desenrolar das mudanças e reformulações da vida em família (FALCÃO; SALOMÃO, 2005).

Relata Dias (1994) que o tornar-se avó significa uma nova etapa para toda a família, pois abrange uma geração a mais. Para elas, avós de meia-idade, a chegada de um neto pode ser uma solução para sua "solidão", por ter "perdido" seus filhos. Assim, a avó adquire uma nova perspectiva de vida tendo importância e utilidade, experimentando de outra forma ser mãe, mas sem as responsabilidades que tinha quando foi mãe. 
De acordo com Teixeira (2005), as mães precisam de encorajamento e cuidados dos profissionais, mas, além disso, as nutrizes necessitam de cuidados intrafamiliares para amamentar seu filho com sucesso.

Algumas mães mostram insegurança e dificuldade para resolver pequenos problemas durante a amamentação, e, nesse instante, a presença da avó, que está presente na maioria das culturas, parece ser importante para elas. Elas presenciam quase todos os nascimentos de seus netos para oferecer ajuda e cuidados (SUSIN, 2004).

Para Araújo (2002), a política de saúde da criança no Brasil tem dado preferência, dentre outras, a ações de promoção, proteção e apoio ao AM, como estratégia fundamental para a redução da mortalidade infantil e para a melhoria da qualidade de saúde das crianças. Nessa "guerra" a favor da lactação natural, é indispensável a participação de todos, principalmente dos familiares, dentre os quais, podemos citar as mulheres-avós.

Envolver a mulher-avó no processo de incentivo ao AM é fundamental, pois o primeiro aprendizado é junto à família, e, quando esse aprendizado é qualificado pelo serviço de saúde, a nutriz e seu bebê são beneficiados. Em caso contrário, as informações prestadas pelo profissional poderão vir a ser fonte de discórdia, contribuindo assim para o desmame precoce (KÖLLER, 2005).

Teixeira (2005) ressalta que estudos feitos em alguns lugares do mundo têm demonstrado a influência das avós no AM. Alguns relatam que essa influência pode favorecer ou dificultar o "andamento" da amamentação.

Estudo realizado na cidade de Florianópolis verificou que as avós, apesar de acharem que o AM é importante para mãe, filho, família e sociedade, reconhecem que viveram em um momento histórico onde se desenvolveu uma cultura em que a prática do AM era desestimulada, quando se proliferava a ideia do leite fraco e pouco, e que não sustentava a criança, complementando com leite em pó (TEIXEIRA et al. 2006).

Quando visualizamos o grau de influência exercida pela mulher-avó, referem Teixeira e Nitschke (2008), é preciso encontrar junto a ela maneiras de trabalhar a amamentação com intuito de promovê-la, protegê-la e apoiá-la ,quando exercer o cuidado intrafamiliar à mulher nutriz. Essa intervenção poderá contribuir para a redução do desmame precoce e, assim, contribuir para a melhoria da 
qualidade de vida das crianças e, futuramente, de adultos mais saudáveis, observado que o AM é um dos cuidados primordiais para o viver.

\section{Atuação do profissional enfermeiro nas ações de estímulo ao aleitamento materno}

O Conselho Federal de Enfermagem (2005) instituiu a lei do Exercício Profissional do Enfermeiro (Lei 7.498/86). Compete a esse profissional a assistência à gestante, parturiente, puérpera e ao recém-nascido, o acompanhamento da evolução de parto, a execução e assistência obstétrica em situação de emergência e a execução do parto natural em gestante de baixo risco.

De acordo com UNICEF (1993), desde o início da gravidez é importante que os profissionais de saúde ofereçam orientação educacional às mulheres, e que sejam capazes de identificar mulheres que estejam correndo risco de enfrentar dificuldades no processo do AM.

Um dos compromissos da enfermagem é de incluir as famílias nos cuidados de saúde. A evidência teórica, prática e investigacional do significado que a família pode ter com um ambiente de harmonia e oferecendo saúde para seus membros, bem como a influência sobre a doença, faz com que as enfermeiras venham a considerar o cuidado focado na família como parte integrante da prática de enfermagem. Todavia, esse enfoque só pode ser alcançado com responsabilidade e respeito, estabelendo-se práticas de avaliação e intervenção confiáveis (WONG, 1999).

As equipes de saúde devem estar capacitadas para acolher a gestante, garantindo orientação de forma apropriada quanto aos benefícios da amamentação para mãe, a criança, a família e a sociedade. Essa informação durante o pré-natal é de fundamental importância para as orientações sobre como o leite é produzido, a importância da amamentação precoce e sob livre demanda, ajudando, assim, a aumentar sua autoconfiança para a capacidade de amamentar e envolver os familiares e a comunidade nesse processo (BRASIL, 2004a).

De acordo com Wong (1999) o enfermeiro, na educação em saúde, assume grande relevância, pois pode, já no pré-natal, informar e discutir com as gestantes as vantagens da amamentação. 
O enfermeiro deverá estar próximo durante o parto, auxiliando as mães. O AM deve ser iniciado o mais precoce possível. Nesse período, o enfermeiro poderá intervir reforçando as orientações, buscando solucionar os problemas, prevenindo e ajudando à superar as dificuldades da puérpera relacionadas ao processo da amamentação, evitando assim a introdução de alimentos complementares precocemente e seus possíveis efeitos (MOURA; RODRIGUEZ; SILVA; 2003).

No pós-parto, os primeiros dias são cruciais para o AM bem sucedido, pois é nesse período que a lactação se estabelece, além de ser um período de intenso aprendizado para a mãe e adaptação do recém-nascido. Daí a importância do acompanhamento intensivo no pós-parto e através de visitas domiciliares após a alta hospitalar, pois várias dúvidas e problemas podem surgir e tornar a mulher vulnerável e insegura (ALMEIDA; FERNANDES; ARAÚJO, 2004).

É necessário o apoio e o estímulo de auxiliares de saúde, especialmente no início do AM, para ajudar nos problemas precoces. Eles estão numa posição chave, tanto nas maternidades quanto nos centros de saúde e clínicas. Devem oferecer à nutriz orientação eficiente, atualizada, acessível à compreensão e transmitida com simpatia e paciência. Devem assegurar a cada mãe que ela realmente pode amamentar (KING, 1998).

Conforme Wong (1999), o enfermeiro no puerpério é o profissional mais envolvido em educar a puérpera acerca da alimentação mais adequada durante o aleitamento, dos exercícios que permitem a melhor ejeção de leite e da adoção de fatores ambientais que influenciem positivamente a implementação de uma experiência ímpar, saudável e prazerosa, durante a amamentação.

Uma mãe que não amamenta facilmente perde a confiança em si mesma e pode se tornar suscetível à pressão de familiares e conhecidos para que desmame. É importante que o profissional faça a mãe se sentir confiante e bem consigo mesma, evitando o emprego de certas palavras (certo, errado, bem, mal, suficiente, problema) que podem ter a ideia de julgamento.

O enfermeiro pode investir em atividades como visitas domiciliares, palestras, grupos de apoio e aconselhamento para incentivo e manutenção do AME, a fim de intensificar as ações promovidas no pós-parto hospitalar, como também, para garantir que o AM continue após o fim da licença-maternidade. Quando a 
nutriz retorna à rotina de trabalho, ela necessita saber como fazer a retirada do leite, conservar, estocar e a forma de administrá-lo à criança, para evitar o desmame precoce (ALMEIDA; FERNANDES; ARAÚJO, 2004).

As lacunas na assistência, decorrentes da ocupação do enfermeiro em atividades administrativas ou por falta de seu número adequado, pode resultar em pouco expressiva atuação do enfermeiro na assistência ao aleitamento materno no pós-parto. Esse fato é preocupante, pois facilita a ocupação desse campo por novas profissões e, como consequência, aumentado o risco de perda desse campo de atuação pelo enfermeiro (ALMEIDA; FERNANDES; ARAÚJO, 2004).

\section{Considerações finais}

A pesquisa teve como metas principais aprofundar o conhecimento sobre a influência da família no aleitamento materno e o papel do enfermeiro como promotor desse ato.

Para que ocorra o sucesso da amamentação, é primordial a vontade da mãe em amamentar, mas também é necessário aprendizado e apoio de familiares, da comunidade, das instituições de saúde e do governo. Nesse contexto, o apoio e o incentivo das pessoas que cercam a mãe, sobretudo o companheiro e/ou as avós da criança, são de suma importância. Mas, para que os pais e as avós possam apoiar e incentivar a amamentação, é necessário que tenham os conhecimentos necessários à prática adequada do aleitamento materno.

Este estudo mostrou que o pai pode ajudar a mãe nesse período e que a participação dele é extremamente benéfica para todas as pessoas envolvidas no processo, fortalecendo também o vínculo entre os pais e seus filhos. Dessa forma, acredita-se que, levado em consideração o contexto cultural, a inclusão do pai nas estratégias de promoção do aleitamento materno mostra-se muito positiva.

As avós, sempre muito próximas à família no momento do nascimento de uma criança, podem exercer influências positivas e negativas na amamentação. Apesar de terem boas intenções, muitas vezes transmitem às filhas e noras a sua experiência com a amamentação, que pode ter sido negativa e, provavelmente, diferente das recomendações atuais. Para que experiências negativas e informações 
errôneas não passem de uma geração a outra, as avós devem ser envolvidas no processo e incluídas nos programas de promoção do AM.

Para nós enfermeiros em função da importância da amamentação, do grau de desenvolvimento do nosso país e das evidências epidemiológicas, a promoção do aleitamento materno deve ser vista como uma ação prioritária para a melhoria da saúde e da qualidade de vida das crianças e de suas famílias. O sucesso dessa prática ocorre à medida que haja uma integração harmoniosa entre mãe, pai, família, contexto social e atuação dos profissionais de saúde.

É necessário destacarmos a importância do enfermeiro no processo de amamentação, ajudando a família a adaptar-se ao novo momento em seu ciclo de vida, abrindo-se à chegada de um “novo ser”. Nessa perspectiva, o estudo demonstrou ser possível ampliarmos as estratégias de promoção ao aleitamento materno, envolvendo a figura paterna e as avós no processo do AM, incentivando e apoiando a nutriz.

\section{The family influence in breast-feeding and the nurse action}

\section{Abstract}

The breast-feeding promotion is the most important intervention to the children morbid and mortality reduction. It stimulates mother and baby entail and it is important to breast-feeding. The maternal milk is the best support to a health growth of a newborn baby. It not depends just a decision about to suckle or not, but a lot of social interaction and conflict lived for the mother. This production discuss about the influence of the family in breast-feeding process. Objective: to talk about the father importance in breast-feeding; to know the grandmothers importance to breast-feeding and; identify the nurse actions to stimulate the breast-feeding. This is a bibliographic search, based in to analysis publications about this theme since 1985 at 2009. By the promotion and consolidation of breast-feeding, it is necessary the continuous actions by Government, health institutions e health professionals, community and family, in special the father and the grand-mothers.

Keywords: Breast-feeding. Father. Woman-grandmother. Role of Nursing. 


\section{Referências}

ALMEIDA, J. A. G. Amamentação: um híbrido natureza-cultura. Rio de Janeiro: Fiocruz, 1999.

ALMEIDA, N. A. M.; FERNANDES, A. G..; ARAÚJO, C. G. Aleitamento materno: uma abordagem sobre o papel do enfermeiro no pós-parto. Revista Eletrônica de Enfermagem, Goiânia, v. 6, n. 3, p. 358-367, set./dez. 2004.

ANTUNES, L. S. et al. Amamentação natural como fonte de prevenção em saúde. Ciência \& Saúde Coletiva, Rio de Janeiro, v. 13, n. 1, p. 103-109, jan./fev. 2008.

ARAÚJO, M. D. Situação e perspectivas do aleitamento materno no Brasil. In: CARVALHO, M. R.; TAMAZ, N. R. Amamentação: bases científicas para a prática profissional. Rio de Janeiro: Guanabara-Koogan, 2002.

ARAÚJO, M. F. M.; BESERRA, E. P.; CHAVES, E. S. O papel da amamentação ineficaz na gênese da obesidade infantil: um aspecto para a investigação de enfermagem. Acta Paulista de Enfermagem, São Paulo, v. 19, n. 4, p. 450455, 2006.

BRASIL. Ministério da Saúde. Aleitamento materno. Brasília: MS, 1995.

BRASIL. Ministério da Saúde. Dez passos para uma alimentação saudável: guia alimentar para crianças menores de dois anos. Brasília: MS, 2002.

BRASIL. Ministério da Saúde. Secretaria de Atenção Básica. Agenda de compromissos para a saúde integral da criança e redução da mortalidade infantil. Brasilia: MS, 2004a.

BRASIL. Ministério da Saúde. Sistemas de informações sobre mortalidade (SIM) e nascidos vivos (Sinasc) para os profissionais do Programa Saúde da Família. 2. ed. Brasilia: MS, 2004b.

BRASIL. Lei $\mathrm{n}^{\circ} \mathbf{1 1 . 2 6 5}$, de 3 de janeiro de 2006. Regulamenta a comercialização de alimentos para lactentes e crianças de primeira infância e também a de produtos de puericultura correlatos. Brasília, 2006. Disponível em: <http://www.planalto. gov.br/ccivil_03/_Ato2004-2006/2006/Lei/L11265.htm>. Acesso em: 16 mar. 2009.

BRASIL. Lei $\mathbf{n}^{\circ}$ 11.770, de 9 de setembro de 2008. Cria o Programa Empresa cidadã, destinado à prorrogação da licença-maternidade. Brasília, 2008. Disponível em: <http://www.planalto.gov.br/ccivil_03/_Ato2007-2010/2008/Lei/L11770. htm>. Acesso em: 16 mar. 2009. 
BRASIL. Ministério da Saúde. Como surgiu a semana mundial de amamentação. Brasilia, 2008b. Disponível em: <http://portal.saude.gov.br/portal/aplicacoes/ noticias/noticias_detalhe.cfm?co_seq_noticia $=51578>$. Acesso em: 22 nov. 2008.

BRASIL. Ministério da Saúde. Materiais informativos: saúde da criança. Brasilia: MS, 2008c.

BRASIL. Ministério da Saúde. Portaria no 2.799, de 18 de novembro de 2008. Institui no âmbito do SUS a Rede Amamenta Brasil. Brasília: MS, 2008d. Disponível em: <http://bvsms.saude.gov.br/bvs/saudelegis/gm/2008/prt2799_ 18_11_2008.html>. Acesso em: 22 nov. 2008.

BRASIL. Ministério da Saúde. Promoção, proteção e apoio ao aleitamento materno. Brasília, 2009. Disponível em: <http://portal.saude.gov.br/portal/saude/ area.cfm?id_area=1460>. Acesso em: 15 mar. 2009.

CONSELHO FEDERAL DE ENFERMAGEM. Lei no 7.498/86, de 26 de junho de 1986. Lei do Exercício Profissional do Enfermeiro. Disponível em: $<$ http://corendf.org.br/site/secoes.asp>. Acesso em: 02 fev. 2009.

DIAS, C. S. B. A importância dos avós no contexto familiar. Psicologia: Teoria e Pesquisa, v.10, n. 1, p. 31-40, jan./fev. 1994.

FALCÃO, D. V. S.; SALOMÃO, N. M. R. O papel dos avós na maternidade adolescente. Estudos de Psicologia, Campinas, v. 22, n. 2, p. 205-212, abr./jun. 2005.

FALCETO, O. G. A influência de fatores psicossociais na interrupção precoce do aleitamento materno. 2002. Tese (Doutorado em Medicina)- Faculdade de Medicina, Universidade Federal Rio Grande do Sul, Porto Alegre, 2002.

FALEIROS, F. T. V.; TREZZA, E. M. C.; CARANDINA, L. Aleitamento materno: fatores de influência na sua decisão e duração. Revista de Nutrição, Campinas, v. 19, n. 5, p. 623-630, set./out. 2006.

FERNANDES, E. R. L. Vivência do homem/pai no processo da amamentação do filho. 2003. Dissertação (Mestrado em Enfermagem)- Departamento de Enfermagem. Universidade Federal do Rio Grande do Norte, Natal, 2003.

FREITAS, W. M. F.; COELHO, E. A. C.; SILVA, A. T. M. C. Sentir-se pai: a vivência masculina sob o olhar de gênero. Cadernos de Saúde Pública, Rio de Janeiro, v. 23, n. 1, jan. 2007. 
GIL, A. C. Como elaborar projetos de pesquisa. 4. ed. São Paulo: Atlas, 2002.

GIUGLIANI, E. R. J. Amamentação: como e por que promover. Jornal de Pediatria, Rio de Janeiro, v. 70, n. 3, p. 138-151, 1994.

GIUGLIANI, E. R. J. O aleitamento materno na prática clínica. Jornal de Pediatria, Rio de Janeiro, v. 76, p. 238 -252, 2000. Suplemento 3.

GIUGLIANI, E. R. J.; VICTORA, C. G.. Normas alimentares para crianças brasileiras menores de 2 anos: embasamento científico. Brasília: OMS/OPAS, 1997.

GUERRERO, M. E. C. A alegria de amamentar. São Paulo: Maltese, 1990.

GUERRERO, M. E. C. Revisitando o desmame precoce através de recortes da história. Revista Latino-Americana de Enfermagem, Ribeirão Preto, v. 10, n. 4, p. 578-585, jul./ago. 2002.

ICHISATO, S. M. T.; SHIMO, A. K. K. Aleitamento materno e as crenças alimentares. Revista Latino-Americana de Enfermagem, Ribeirão Preto, v. 9, n. 5, p. 70-76, set. 2001.

KING, F. S. Como ajudar as mães a amamentar. 3. ed. Brasília: MS, 1998.

KIPPER, C. D. R.; LOPES, R. S. O tornar-se avó no processo de individuação. Psicologia: Teoria e Pesquisa, Brasília, v.22, n.1, p. 29-34, jan./abr. 2006.

KÖLLER, C. V. F. Vivências da adolescente no aleitamento materno e participação de sua mãe nesse processo. 2005. Dissertação (Mestrado em Enfermagem)Universidade Federal do Rio Grande do Sul, Porto Alegre, 2005.

LAKATOS, E. M.; MARCONI, M. A. Metodologia do trabalho científico. 3. ed. São Paulo: Atlas, 2001.

LAMOUNIER, J. A. O efeito de bicos e chupetas no aleitamento materno. Jornal de Pediatria, Rio de Janeiro, v. 79, n. 4, p. 284-286, 2003.

LAMOUNIER, J. A.; VIEIRA, G. O.; GOUVÊA, L. C. Composição do leite humano: fatores nutricionais. In: REGO J. D. Aleitamento materno. São Paulo: Atheneu, 2001.

LANA, A. P. B. Manual de amamentação: criança amamentada é criança feliz, segura, inteligente e saudável. São Paulo: Janssen-Cilag, 1999. 
LANA, A. P. B. O livro de estímulo à amamentação: uma visão biológica, fisiológica e psicológica comportamental da amamentação. São Paulo: Atheneu, 2001.

MARTINS, J. F. Evolução do aleitamento materno no Brasil. In: REGO, J. D. Aleitamento materno. Rio de Janeiro: Atheneu, 2000.

MONSON, M. R. R. Programa nacional de incentivo ao aleitamento materno. Brasília: MS, 1991.

MONTE, C. M. G. et al. Guia alimentar para crianças menores de dois anos. Brasilia: MS, 2002.

MONTEIRO, J. C. S. Contato precoce e amamentação em sala de parto na perspectiva da mulher. 2006. Dissertação (Mestrado em Enfermagem)-Escola de Enfermagem de Ribeirão Preto, Universidade de São Paulo, Ribeirão Preto, 2006.

MOTTA, C. C. L.; CREPALDI, M. A. O pai no parto e apoio emocional: a perspectiva da parturiente. Paideia, Ribeirão Preto, v. 15, n. 30, p. 105-118, 2005.

MÜLLER, F. S. Representações sociais de um grupo de nutrizes sobre o apoio no processo de amamentação. 2008. 82 f. Dissertação (Mestrado em Enfermagem)Escola de Enfermagem, Universidade de São Paulo, São Paulo, 2008.

MURAHOVSCHI, J. et al. Amamentação: da teoria à prática: manual para profissionais da saúde. Santos: Fundação Lusíada, 1999.

OLIVEIRA, D.; SILVA, L. A. S. A percepção de um grupo de gestantes sobre a atuação do enfermeiro no pré-natal. In: CONGRESSO CIENTÍFICO CEULP/ ULBRA, 4., 2005, Palmas. Anais eletrônicos... Disponível em: $<$ http://www.ulbrato.br/eventos/congresso2005/esteArtigos Aprovados.aspx>. Acesso em: 12 out. 2008.

ORGANIZAÇÃO MUNDIAL DA SAÚDE. Evidências científicas dos dez passos para o sucesso no aleitamento materno. Brasília: Organização Pan-Americana de Saúde, 2001.

REGO, J. D. Aleitamento materno: um guia para pais e familiares. São Paulo: Atheneu, 2002.

RICCO, R. G.; DEL CIAMPO, L. A.; ALMEIDA, C. A. N. Aleitamento materno: passagens e transferências mãe-filho. São Paulo: Atheneu, 2004. 
SALOMONE, R. Um é pouco, dois é bom, três pode ser demais. Veja, São Paulo, ano 38, n. 24, 15 jun. 2005.

SANTOS, E. K. A. Aleitamento materno. In: SCHMITZ, E. M. R. A enfermagem em pediatria e puericultura. São Paulo: Atheneu, 2005.

SANTOS, V. L. F.; SOLER, Z. A. S. G.; AZOUBEL, R. Alimentação de crianças no primeiro semestre de vida: enfoque no aleitamento materno exclusivo. Revista Brasileira de Saúde Materno Infantil, Recife, v. 5, n. 3, p. 283-291, jul./ set. 2005.

SENA, M. C. F.; SILVA, E. F.; PEREIRA, M. G.. Prevalência do aleitamento materno nas capitais brasileiras. Revista da Associação Médica Brasileira, São Paulo, v. 53, n. 6, p. 520-524, 2007.

SILVA, A. A. M. Amamentação: fardo ou desejo? Estudo histórico-social dos saberes e práticas sobre aleitamento materno na sociedade brasileira. 1990. Dissertação (Mestrado em Medicina)-Faculdade de Medicina de Ribeirão Preto, Universidade de São Paulo, Ribeirão Preto, 1990.

SILVA, I. A. Amamentar: uma questão de assumir riscos ou garantir benefícios. São Paulo: Robe, 1997.

SIQUEIRA, R. S.; MONTEIRO, C. A. Amamentação na infância e obesidade na idade escolar em famílias de alto nível socioeconômico. Revista de Saúde Pública, São Paulo, v. 41, n. 1, p. 5-12, fev. 2007.

SOARES, E. M. S. et al. Uso de chupeta e sua relação com o desmame precoce em população de crianças nascidas em hospital amigo da criança. Jornal de Pediatria, Rio de Janeiro, v. 79, n. 4, p. 309-16, 2003.

SOCIEDADE BRASILEIRA DE PEDIATRIA. Pioneiras no apoio: entrevista com Rose Teykal do grupo de mães amigas do peito. 2008. Disponível em: <http:// www.sbp.com.br/show_item2.cfm?id_categoria $=$ 65\&id_detalhe=2819\&tipo_ detalhe $=$ s $>$. Acesso em: 21 nov. 2008.

SOCIEDADE DE PEDIATRIA DE SÃO PAULO. Amamentação na primeira hora, proteção sem demora. 2007. Disponível em: <http://www.spsp.org.br/ spsp_2008/materias.asp?Id_Pagina=152\&subseção=103>. Acesso em: 03 fev. 2009.

SOUSA, L. A. Promoção: apoio ao aleitamento materno: binômio ou antítese? Uma caracterização das práticas do profissional de saúde na perspectiva da mulher que no processo do aleitamento materno. 2006. 188 f. Dissertação (Mestrado em 
Enfermagem)-Escola de Enfermagem de Ribeirão Preto, Universidade São Paulo, Ribeirão Preto, 2006.

SUSIN, L. R. O. Influência do pai e das avós no aleitamento materno. 2004. $141 \mathrm{f}$. Tese (Doutorado em Medicina)-Faculdade de Medicina, Universidade Federal do Rio Grande do Sul, Porto Alegre, 2004.

SUSIN, L. R. O.; GIUGLIANI, E. R. J.; KUMMER, S. C. Influência das avós na prática do aleitamento materno. Revista de Saúde Pública, São Paulo, v. 39, n. 2, p. 141-147, abr. 2005.

TEIXEIRA, M. A. et al. Significados de avós sobre a prática do aleitamento materno no cotidiano familiar: a cultura do querer-poder amamentar. Texto \& Contexto: enfermagem, Florianópolis, v. 15, n. 1, p. 98-106, jan./mar. 2006.

TEIXEIRA, M. A. Meu neto precisa mamar! E agora? Construindo um cotidiano de cuidado junto a mulheres-avós e sua família em processo de amamentação: um modelo de cuidar em enfermagem fundamentado no interacionismo simbólico. 2005. 236 f. Dissertação (Mestrado em Enfermagem)- Faculdade de Enfermagem, Universidade Federal de Santa Catarina, Florianópolis. 2005.

TEIXEIRA, M. A.; NITSCHKE, R. G. Modelo de cuidar em enfermagem junto às mulheres-avós e sua família no cotidiano do processo de amamentação. Texto \& Contexto: enfermagem, Florianópolis, v. 17 n. 1, jan./mar. 2008.

TOMA, T. S.; REA, M. F. Benefícios da amamentação para a saúde da mulher e da criança: um ensaio sobre as evidências. Cadernos de Saúde Pública, Rio de Janeiro, v. 24, p. s235-s246, 2008. suppl. 2.

UNICEF. Grupo de Defesa da Saúde da Criança. Manejo e promoção do aleitamento materno. Programa nacional de incentivo ao aleitamento materno. Brasília: OMS/OPAS/UNICEF, 1993.

WONG, D. L. Enfermagem pediátrica: elementos essenciais à intervenção efetiva. 5. ed. Rio de Janeiro: Guanabara-Koogan, 1999. 